\title{
Barriers Faced by Family Medicine Graduates Interested in Performing Obstetric Deliveries
}

\author{
Tyler W. Barreto, MD, Aimee R. Eden, PhD, MPH, Elizabeth Rose Hansen, and \\ Lars E. Peterson, $M D, P h D$
}

Fewer family physicians are providing deliveries, which raises concern for access to obstetric care. We found that among recent family medicine graduates who would like to do deliveries, difficulty finding a position that supports including deliveries was a major barrier. ( $\mathrm{J}$ Am Board Fam Med 2018;31:

332-333.)

Keywords: Childbirth, Family Physicians, Family Practice, Obstetric Delivery, Parturition, Pregnancy

Maternal and infant mortality is increasing in the United States, attributed in part to poor access to maternity care. ${ }^{1,2}$ Further obstetrician/gynecologist shortages are projected ${ }^{3}$, especially in rural communities. ${ }^{4}$ Exacerbating this problem is the rapidly decreasing proportion of family physicians doing obstetric deliveries despite findings that family physicians have similar outcomes to obstetricians. ${ }^{5,6}$ Nearly a quarter of recent family medicine residency graduates want to include obstetric deliveries in their practice ${ }^{7}$, which suggests any barriers for family physicians to include obstetrics (OB) in their practice extend beyond personal preference.

To identify the barriers for recent graduates intending to practice obstetrics, we analyzed data from the 2016 Family Medicine National Graduate Survey. Following a question that asked, "are you

This article was externally peer reviewed.

Submitted 1 November 2017; revised 20 January 2018; accepted 23 January 2018.

From UT Health San Antonio, San Antonio, TX (TWB); American Board of Family Medicine, Lexington, KY (ARE, ERH, LEP).

Funding: none.

Conflict of interest: Drs. Eden and Peterson and Ms. Hansen are employees of the American Board of Family Medicine.

Corresponding author: Tyler W. Barreto, MD, 7703 Floyd Curl Drive MC 7795, San Antonio, TX 78229-3900 (E-mail: barreto@uthscsa.edu).

See Related Commentary on Page 328. currently delivering babies?" Respondents who indicated that they were not delivering babies were asked why they were not, with a "select all that apply" list of 9 response options.

Of the 2018 respondents who provided direct patient care, $87 \%$ indicated they did not deliver babies. We excluded the 889 respondents who selected "not interested" as a reason. Of the 865 respondents left, almost $60 \%$ reported that the opportunity to do deliveries was not available in the practice they joined and/or that lifestyle considerations influenced their decision not to include deliveries (Figure 1).

New family physicians who are interested in including deliveries in practice are poised to play a critical role in increasing access to obstetric care if the primary barriers are identified and addressed.

Figure 1. Reasons new family physicians who are interested in delivering babies are not currently doing so. $\mathbf{N}=865$.

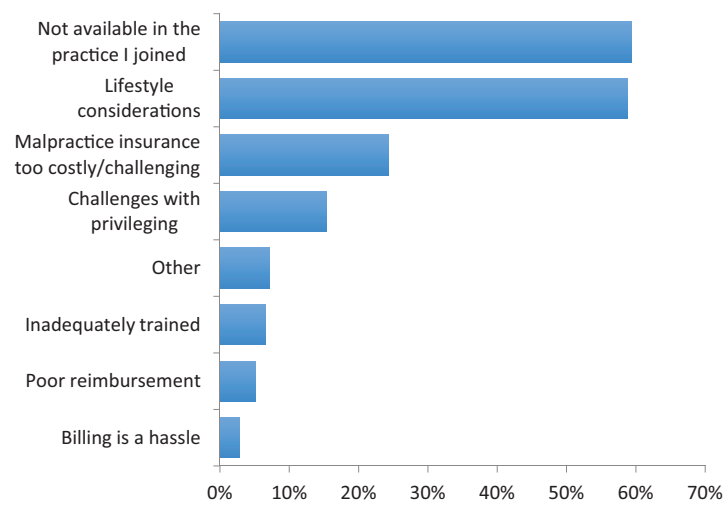


Availability of family medicine positions that include obstetrics seems necessary to increase the number of family physicians practicing obstetrics. Lifestyle considerations may be mitigated by implementing call sharing structures. Removing barriers to family physicians who want to include obstetrics would increase access to care and may be part of the solution to the maternal morbidity problem.

To see this article online, please go to: http://jabfm.org/content/ 31/3/332.full.

\section{References}

1. Hung P, Henning-Smith CE, Casey MM, Kozhimannil KB. Access to obstetric services in rural counties still declining, with 9 percent losing services, 2004-14. Health Aff (Millwood) 2017;36: 1663-71.

2. Pregnancy Mortality Surveillance System । Pregnancy | Reproductive Health I CDC. Available from: https://www.cdc.gov/reproductivehealth/maternalin fanthealth/pmss.html. Published June 29, 2017. Accessed October 24, 2017.

3. Rayburn WF. The obstetrician-gynecologist workforce in the United States. Washington, DC: American Congress of Obstetricians and Gynecologists; 2011:119-35. Available from: https://www.acog.org/ /media/BB3A7629943642ADA47058D0BDCD 1521.pdf. Accessed September 28, 2017.

4. ACOG Committee Opinion No. 586. Health disparities in rural women. Obstet Gynecol 2014;123: 384-8.

5. Barreto T, Peterson LE, Petterson S, Bazemore AW. Family physicians practicing high-volume obstetric care have recently dropped by one-half. Am Fam Physician 2017;95:762.

6. Avery DM, Waits S, Parton JM. Comparison of Delivery Related Complications among Obstetrician/Gynecologists and Family Physicians Practicing Obstetrics. Am J Clin Med 2014:10:21-5.

7. Barreto TW, Eden AR, Petterson S, Bazemore AW, Peterson LE. Intention Versus Reality: Family Medicine Residency Graduates' Intention to Practice Obstetrics. J Am Board Fam Med 2017;30:405-6. 